\title{
Diabetes and male sexual function
}

\author{
Khaleeq Rehman MBBS MS, Evette Beshay MD PhD, Serge Carrier MD FRCSC
}

\section{K Rehman, E Beshay, S Carrier. Diabetes and male sexual function. J Sex Reprod Med 2001;1(1):29-33.}

Diabetes mellitus (DM) is the most common cause of erectile dysfunction (ED). Up to $28 \%$ of men complaining of ED have $\mathrm{DM}$ as the primary causative factor. DM should be considered in all patients presenting with ED. Known diabetic men should be encouraged to have excellent control of their DM to avoid not only the chronic complications of DM but also its acute effects, especially the effect of hyperglycemia on erectile function. The physiological impact of diabetes on sexual function in men is reviewed.

Key Words: Diabetes mellitus; Ejaculation; Erectile dysfunction; Sexual function; Sexuality

Cexuality is an important aspect in the lives of most indiSviduals and couples. Normal sexual function involves, however, the interaction and coordination of multiple components, including psychological, physiological, social, religious and emotional factors. Chronic medical conditions, such as diabetes, may have an impact on many of these components, not only physiologically, but also psychologically. Over two million Canadians are afflicted with diabetes, the majority (90\%) with type 2 diabetes, which is the most common form of adult diabetes. The prevalence of diabetes increases with age. The number of people with diabetes is expected to grow substantially as the population ages. Diabetes has a detrimental effect on sexual function. The present article briefly reviews the physiological impact of diabetes on sexual function in men.

\section{Diabetic erectile dysfunction}

Diabetes mellitus (DM) is the most common cause of erectile dysfunction (ED) (1). Up to $28 \%$ of men who complain of ED have DM as the primary causative factor (2).

\section{Diabète et fonctionnement sexuel chez les hommes}

RÉSUMÉ : Le diabète sucré (DS) est la cause la plus fréquente de dysérection; il en est le principal facteur étiologique jusque dans $28 \%$ des cas. Le DS devrait être envisagé chez tous les patients qui consultent pour de la dysérection. Il faudrait inciter les hommes diabétiques à maîtriser parfaitement leur glycémie pour éviter non seulement les complications chroniques du DS mais aussi ses effets immédiats, notamment l'effet de l'hyperglycémie sur le fonctionnement érectile. Il sera question, dans le présent article, des répercussions physiologiques du diabète sur le fonctionnement sexuel chez les hommes.

Department of Surgery, Division of Urology, McGill University, Montreal, Quebec

Correspondence: Dr S Carrier, Department of Urology, McGill University Health Center, 687 Pine Avenue West S6-92, Montreal, Quebec H3A 1A1. Telephone 514-842-1231 ext 4302, fax 514-843-1552, e-mail sergecarrier@vl.videotron.ca 
The pathophysiology of ED in diabetes is not well understood (9). Associated neuropathy or vasculopathy (microangiopathy and generalized vascular disease) is considered to be the most important factors in the pathophysiology of DM-induced ED (10).

Recently, attention has been increasingly directed toward understanding the role of vascular endothelium and its control of penile cavernous smooth muscle tone (11). The two corpus cavernosum, which are the erectile bodies of the penis, consist of multiple lacunar spaces surrounded by cavernous smooth muscle. These lacunar spaces are lined by the endothelium. During sexual activity, neurotransmitters (nitric oxide [NO] being the most important) are released from either the penile nerve ending or the endothelium that triggers a relaxation of both cavernosal arteries and smooth muscle. This increases penile blood flow, causes dilation of the lacunar space and, eventually, an erection. In DM, it has been shown that endothelium-dependent smooth muscle relaxation is impaired, although the exact mechanism is not known (12,13). Endothelial dysfunction (the small ed) then leads to erectile dysfunction (the big ED) through smooth muscle dysfunction in the microvascular tree of the penis.

Acute hyperglycemia alone may induce endothelial dysfunction and also decrease the velocity of nerve conduction in rodents $(14,15)$. Chronic hyperglycemia is associated with the loss of myelinated and unmyelinated fibres and attenuated nerve fibre regeneration. Diffuse abnormalities of the peripheral nerve vasculature (vasa nervosum) are well documented in diabetics (16-20). In the late stages of diabetes, there may be complete vascular occlusion with atherosclerosis, thickening of capillary basement membrane, dilation and microaneurysms of capillaries as well as endothelial hyperplasia, and desquamation and degeneration of pericytes (21-25). These lesions induce a microangiopathy that leads to endoneurial hypoxia and demyelination. The lesions decrease the blood flow to the vaso nervosum and, thus, lead to nerve ischemia (26). A peripheral neuropathy then develops, which initially affects small unmyelinated fibres. Around $61.2 \%$ of diabetics who present with impotence show evidence of neuropathy (27).

In erectile tissue, there is atrophy of the smooth muscle cells and lipid deposition in the corpus cavernosum (24). Urogenital nerves also show morphological alterations, nerve conduction is impaired and neurotransmitter levels are altered (28-32). Vasoactive intestinal polypeptide immunoreactivity, and acetylcholine synthesis and release have been shown to be reduced in nerves from diabetic patients $(33,34)$. In the penis, smooth muscle shows impaired neurogenic and endothelium-dependent relaxation $(35,36)$. The dorsal nerve of the penis is involved in erectile response. In diabetics, the conduction velocity of the dorsal nerve is significantly slower than that in normal males and can be demonstrated with the bulbocavernous reflex (37). Unfortunately, differences in bulbocavernous reflex latency are not useful for differentiating diabetics from nondiabetics $(38,39)$. Autonomic nerve testing is found to be abnormal in $63 \%$ of patients with diabetic ED (40).
Although autonomic nerve testing is found to be abnormal in up to $63 \%$ of patients with diabetic ED, some studies have shown no difference from control values.

NO has been identified as the principal neurotransmitter causing the relaxation of penile cavernous smooth muscle. This smooth muscle relaxation increases arterial blood flow and produces an erection. It has been shown in diabetic rats that NO synthase, the enzyme that catalyses the production of $\mathrm{NO}$ in cavernosal tissue, decreased even with insulin treatment (41). The ED in these diabetic rats did not improve, suggesting that permanent nerve injury to the nonadrenergic, noncholinergic nerves may contribute to abnormal response.

Oxidative stress has recently been implicated in the pathogenesis of diabetic complications. The deleterious effects of high glucose concentrations on cultured Schwann or endothelial cells appear to be related, in part, to rates of glucose auto-oxidation to advanced glycosylation end products (42). In the course of glucose auto-oxidation, hydrogen peroxide is generated from molecular oxygen via the dismutation of superoxide anion, thus exerting an additional oxidative stress. The interaction of advanced glycosylation end products with sulfhydryl-containing proteins, altered prostanoid production, and ischemia/reperfusion are further important sources of reactive oxygen species (ROS) in diabetic tissues (43). Interestingly, insulin itself may, under certain circumstances, activate a membrane-bound hydrogen peroxide generating system that could theoretically exacerbate oxidative stress in susceptible tissues (44). This oxidative stress, in turn, may conceivably exhaust local antioxidant defenses and thereby promote lipid peroxidation of cellular membranes, cytoskeletal damage and ultimately cellular degeneration. Furthermore, mitochondrial DNA mutations have been reported in diabetic tissues (45), suggesting oxidative stress-related mitochondrial damage. Attention has also been recently focused on the role of ROS in vascular dysfunction in diabetes, particularly regarding the reaction of $\mathrm{NO}$ with superoxide anion to form peroxynitrate, a very potent ROS (46).

The clinical affect of DM on penile blood flow has been well documented. Patients with insulin-dependent diabetes and associated coronary artery disease have significantly more severe disease related to the cavernosal artery than noninsulin-dependent diabetic patients (47). Benvenuti et al (48) proposed that, in diabetic ED, vascular obstruction is a more important factor than nerve damage. The main complication of diabetes is atherosclerosis. Increased activation of protein kinase $\mathrm{C}$, overexpression of endothelin and angiotensin II, increased synthesis of diacylglycerol, oxidative stress and increased production of plasminogen activator inhibitors are considered to promote vascular pathology in diabetic patients with ED (11).

$\mathrm{DM}$ is often associated with other ED risk factors such as hypertension, dyslipidemia and smoking. In patients with these additional factors, the incidence of ED increases. Also, up to $30 \%$ of diabetic men will have psychogenic factors that further compound their diagnosis (3). 
The relative importance of these cofactors varies among individuals. ED, when caused by DM, tends to be more severe than with other etiologies.

The clinical assessment and management of diabetic men with ED are similar to those used for other causes of ED. It must not be forgetten, however, that ED may be the presenting symptom of undiagnosed diabetes. Furthermore, poorly controlled DM exacerbates ED, and the primary goal of treatment is to avoid hyperglycemia.

In diabetic ED, oral therapy is the best first line treatment. Currently, the only effective oral treatment is sildenafil, provided that there are no specific contraindications. In a large double-blind placebo study of 268 diabetic men with ED, erections were improved in $57 \%$ of patients who received sildenafil compared with $10 \%$ of men who received placebo. Sexual intercourse was successful in $48 \%$ of men receiving sildenafil compared with $12 \%$ of men who were given a placebo (49).

If oral therapy is not effective, a number of other options are available such as a vacuum erection device (VED), an intraurethral prostin, an intracavernosal injection (ICI) of an vasoactive substance or penile implantation. Individual patient preferences often determine the next step.

ICI provides satisfactory sexual activity in $72.5 \%$ of patients with DM ED. The optimal dose is usually higher than that for the general population with ICI. Fifty-five per cent of patients require more than $20 \mu \mathrm{g}$ of prostaglandin $\mathrm{E}_{1}$. The dropout rate is high, however, and complaints of penile pain are reported in $61 \%$ of patients; however, it is tolerated by most patients (50). Although less efficacious than ICI, an intraurethral prostin can be a good alternative for patients who do not wish more invasive therapies.

VEDs have been found to be effective in up to $75 \%$ of diabetic men (51). In many patients with diabetic impotence, a significant vascular component exists that renders ICI ineffective. In a male study of ICI failures, when a VED was used in 10 patients, five patients were able to have satisfactory sexual intercourse with this device (52).

When all other treatments are ineffective or unacceptable to a patient, penile prosthesis remains the final treatment of choice (53). It is invasive, expensive and produces irreversible damage to the penile architecture, but under optimal conditions, it can be an excellent treatment option. Presently, the risk of infection has been reduced and recent studies show a lower incidence of infection in diabetic patients (54).

\section{Diabetes and fertility}

Lower pregnancy rates have been associated with diabetes and raise the issue of the basic fertility potential in diabetic men. Variations of semen quality have been reported in diabetic men $(55,56)$. Semen analysis may reveal decreased sperm motility and density, abnormal morphology and generally increased seminal plasma abnormalities. In addition, diabetic men may have decreased serum testosterone due to impaired Leydig cell function (57). Insulin can cross the blood-testis barrier, but its level in seminal plasma has not been shown to correlate significantly with semen parameters (58). Abnormal sperm morphology in diabetic men is associated with an increased level of certain amino acids in the ejaculate (59) and may contribute to reduced fertilization rates. However, the mechanisms of altered spermatogenesis in diabetic men are poorly understood.

\section{Diabetes ejaculatory dysfunction}

The ejaculation reflex is initiated by cerebral erotic input and by sensory stimulation of the penis. The sensory afferent nerves are the dorsal nerves of the penis. Ejaculation is primarily a sympathetic event. The efferent neural pathways arise from spinal levels T10 to L2 and travel through the sympathetic chain ganglia, the hypogastric plexus anterior to the aorta and the pelvis to the prostate, vas deferens and seminal vesicle (60). Ejaculatory dysfunction can be caused by medication such as selective serotonin reuptake inhibitors, surgery such as transurethal resection of the prostate or chronic medical disorders. Diabetes is one of the nonsurgical causes of ejaculatory dysfunction. Diabetic neuropathy affects the peripheral sympathetic nerve supply to the bladder neck, thereby interfering with its closure and resulting in ejaculation abnormalities (61).

Impairment of the sympathetic system results in retrograde ejaculation, that is, the escape of the seminal fluid from the posterior urethra back to the bladder. The diagnosis is made from the patient's medical history (absence of intermittent emission of semen, orgasm without visible ejaculate) and confirmed by finding sperm in postcoital specimen of urine. The presence of more than 10 to 15 sperm per high power field confirms the presence of retrograde ejaculation. More extensive neuropathy may render diabetic men incapable of seminal emission (anejaculation) caused by disruption of the sympathetic nerve supply to the vas deferens.

Sympathomimetic agents may be useful in the treatment of retrograde ejaculation. They act to stimulate the contraction of the bladder neck, prostate, seminal vesicles and vasa deferentia. Imipramine hydrochloride (75 mg bid), a tricyclic antidepressant that blocks norepinephrine reuptake at nerve terminal and potentiates peripheral adrenergic activity, may be the best agent to treat retrograde ejaculation in diabetic patients $(62,63)$. Alpha-adrenergic sympathomimetic medications such as pseudoephedrine (60 mg four times daily), ephedrine or phenylpropanolamine enhance antegrade ejaculation (62-64). Alpha-adrenergic agents may aid in restoring closure of the bladder neck.

If medical therapy fails, sperm can be retrieved from postcoital urine samples and used for insemination (65). Poor results with these methods may be related to the acidic and hyperosmotic condition of the urine, and the effect on sperm function. Results can be improved by altering the composition of the urine. A common method involves consumption of sodium bicarbonate before ejaculation to alkalize the urine $(66,67)$. In addition to the use of sodium bicarbonate, some physicians suggest monitoring and adjusting urine osmolarity to better mimic physiological conditions. Also, instructing the patient to void postejaculation urine in 
buffered media to decrease the detrimental effects of urine was found to be helpful $(66,68)$.

In the case of anejaculation, penile vibratory or electroejaculation using an electrical probe can be successful and has been applied to the diabetic patient (69). Epididymal or testicular sperm aspiration and intracytoplasmic sperm injection can be applied when all else fails.

\section{SUMMARY}

DM should be considered in all men presenting with ED. Fasting blood sugar levels are usually sufficient to screen most men. Known diabetics should be encouraged to have excellent control of their DM to avoid not only the chronic complications of DM, but also acute effects, especially, those of hyperglycemia on erectile activity. Prevention is a key factor with DM. Patients should avoid any factors that can increase the risk of ED. Smoking is probably the most detrimental cofactor of diabetes that increases atherosclerosis. Dyslipidemia, hypertension and obesity are also cofactors that must be controlled to decrease the incidence of not only ED, but also heart disease. In the future, it may be possible that antioxidants will be recommended for diabetic patients to prevent chronic complications. Research is still required to prevent long term complications because they can occur even in well controlled diabetic patients.

\section{REFERENCES}

1. Takahashi Y, Iwamoto Y. Sexual dysfunction in diabetes mellitus. Nippon Rinsho 1997;55:2991-5.

2. Maatman TJ, Montague DK, Martin LM. Erectile dysfunction in men with diabetes mellitus. Urology 1987:29:589-92.

3. Minhas S, Eardley I. Diabetic impotence. In: Carson CC, Kirby RS, Goldstein I, eds. Textbook of Erectile Dysfunction. Oxford: Isis Medical Publishers, 1998:531-40.

4. McCulloch DK, Young RJ, Prescott RJ, et al. The natural history of impotence in diabetic men. Diabetologia 1984;26:437-40.

5. Naliboff BD, Rosenthal M. Effects of age on complications in adult onset diabetes. J Am Geriatr Soc 1989;37:838-42.

6. Klein R, Klein BE, Lee KE, et al. Prevalence of self-reported erectile dysfunction in people with long term IDBM. Diabetes Care 1996;19:135-41.

7. Hakim LS, Goldstein I. Diabetic sexual dysfunction. Endocrinol Metab Clin North Am 1996;25:379-400.

8. Fani K, Lundin AP, Beyer MM, Jimenez FA, Friedman EA. Pathology of the penis in long-term diabetic rats. Diabetologia 1983;25:424-8.

9. McVary KT, Rathnau CH, McKenna KE. Sexual dysfunction in the diabetic BB/WOR rat: A role of central neuropathy. Am J Physiol 1997;272:R259-67. (Abst)

10. Vidal Moreno JF, Moreno Pardo B, Jimenez Cruz JF. Echo-Doppler in diabetic erectile dysfunction. Actas Urol Esp 1996;20:247-54.

11. Calles-Escandon J, Cipolla M. Diabetes and endothelial dysfunction: A clinical perspective. Endocr Rev 2000;22:36-52.

12. Yildirim S, Ayan S, Sarioglu Y, Gultekin Y, Butuner C. The effects of long-term oral administration of L-arginine on the erectile response of rabbits with alloxan-induced diabetes. BJU Int 1999;83:679-85.

13. Saenz de Tejada I, Goldstein I, Azadzoi K, Krane RJ, Cohen RA. Impaired neurogenic and endothelium-mediated relaxation of penile smooth muscle from diabetic men with impotence. N Engl J Med 1989;320:1025-30.

14. Bohlen HG, Lash JM. Topical hyperglycemia rapidly suppresses
EDRF-mediated vasodilatation of normal arterioles. Am J Physiol 1993;265:H219-25.

15 Taylor PD, Poston L. The effect of hyperglycemia on function of rat isolated mesenteric resistance artery. Br J Pharmacol 1994;113:801-8.

16. Hsueh WA, Anderson PW. Hypertension, the endothelial cell, and the vascular complications of diabetes mellitus. Hypertension 1992;20:253-63.

17. Ruderman NB, Williamson JR, Brownlee M. Glucose and diabetic vascular disease. FASEB J 1992:;6:2905-14.

18. Fani K, Lundin AP, Beyer MM, Jimenez FA, Friedman EA. Pathology of the penis in long-term diabetic rats. Diabetologia 1983;25:424-8.

19. Williams E, Timperley WR, Ward JD, Duckworth T. Electron microscopical studies of vessels in diabetic neuropathy. J Clin Pathol 1980;33:462-70.

20. Guirguis WR. Impotence in diabetes: facts and fiction. Diabet Med 1992;9:287-9.

21. Krane RJ, Goldstein I, Saenz de Tejada I. Impotence. N Engl J Med 1989;321:1648-59.

22. Spark RF, White RA, Connolly PB. Impotence is not always psychogenic. New insights into hypothalamic-pituitarygonadal dysfunction. JAMA 1980;243:750-5.

23. Newman HF, Northup JD. Mechanisms of human penile erection: An overview. Urology 1981;17:399-408.

24. Christensen GC. Angioarchitecture of the canine penis and the process of erection. Am J Anat 1954;95:227-50.

25. Newman HF, Northup JD. Mechanisms of human penile erection. Invest Urol 1964;1:350-3.

26. Jensen T, Bjerre-Knudsen J, Feldt-Rasmussen B, Deckert T. Features of endothelial dysfunction in early diabetic nephropathy. Lancet 1989;i:461-3.

27. Yamaguchi Y, Kumamoto Y. Etiological analysis of male diabetic erectile dysfunction with particular emphasis on findings vascular and neurological examinations. Nippon Hinyokika Gakkai Zasshi 1994;85:1474-83.

28. Montague DK, James RE Jr, deWolfe VG, Martin LM. Diagnostic evaluation, classification and treatment of men with sexual dysfunction. Urology 1979;14:545-8.

29. Fearman I, Glocer L, Fox D, Jadzinsky MN, Rapaport M. Impotence and diabetes: Histological studies of the autonomic nervous fibers of the corpora cavernos in impotent diabetic males. Diabetes 1974;23:971-6.

30. Daniels JS. Abnormal nerve conduction in impotent patients with diabetes mellitus. Diabetes Care 1989;12:449-54.

31. Crowe R, Lincoln J, Blacklay PF, Pryor JP, Lumley JS, Burnstock G. Vasoactive intestinal polypeptide-like immunoreactive nerves in diabetic penis. A comparison between streptozotocin-treated rats and man. Diabetes 1983;32:1075-7.

32. Blanco, Saenz de Tejada I, Goldstein I, Krane RJ, Wotiz HH, Cohen RA. Dysfunctional penile cholinergic nerves in diabetic impotent men. J Urol 1990;144:278-80.

33. Zorgniotti AW, Lizza E. Nonprosthetic surgical strategies for impotence. Urol Radiol 1988;10:151-5.

34. Lue TF. Physiology of erection and pathohpysiology of impotence. In: Walsh PC, Retik AB, Stamey TA, Vaughan ED Jr, eds. Campbell's Urology, 6th edn. Philadelphia: WB Saunders, 1992:709-28.

35. Saenz de Tejada I, Goldstein I, Azadzoi K, Krane RJ, Cohen RA. Impaired neurogenic and endothelium-mediated relaxation of penile smooth muslce from diabetic men with impotence. N Engl J Med 1989;320:1025-30.

36. Azadzoi KM, Saenz de Tejada I. Diabetes mellitus impairs neurogenic and endothelium dependent relazation of rabbit corpus cavernosum smooth muscle. J Urol 1992;148:1587-91.

37. Lin JT, Bradley WE. Penile neuropathy in insulin-dependent diabetes mellitus. J Urol 1985;133:213-5.

38. Fishel B, Chen J, Alon M, Zhukovsky G, Matzkin H. The value of testing pudendal nerve conduction in evaluating erectile dysfunction in diabetics. Int J Impot Res 2000;12:103-5.

39. Ho KH, Ong BK, Chong PN, Teo WL. The bulbocavernosus reflex in the assessment of neurogenic impotence in diabetic and non-diabetic men. Ann Acad Med Singapore 1996;25:558-61.

40. Bird SJ, Hanno PM. Bulbocavernosus reflex studies and 
autonomic testing in the diagnosis of erectile dysfunction. J Neurol Sci 1998;154:8-13.

41. Vernet D, Cai L, Garban H, et al. Reduction of penile nitric oxide synthase in diabetic BB/WORdp (Type I) and BBZ/WORdp (type II) rats with erectile dysfunction. Endocrinology 1995;136:5709-17.

42. Ceriello A, dello Russo P, Amstad P, Cerutti P. High glucose induces antioxidant enzymes in human endothelial cells in culture. Evidence linking hyperglycemia and oxidative stress. Diabetes 1996;45:471-7.

43. Baynes JW. Role of oxidative stress in development of complications in diabetes. Diabetes 1991;40:405-12.

44. Krieger-Brauer $\mathrm{HI}$, Kather $\mathrm{H}$. The stimulus-sensitive $\mathrm{H}_{2} \mathrm{O}_{2}-$ generating system present in human fat-cell plasma membrane is multi-receptor-linked and under antagonistic control by hormones and cytokines. Biochem J 1995;307:543-8.

45. Lee HC, Song YD, Li HR, et al. Mitochondrial gene transfer ribonucleic acid (tRNA)Leu(UUR) 3243 and (tRNA)Lys 8344 mutations and diabetes mellitus in Korea. J Clin Endocrinol Metabol 1997;82:372-4.

46. Cameron NE, Cotter MA. Impaired contraction and relaxation in aorta from streptozotocin-diabetic rats: Role of polyol pathway activity. Diabetologia 1992;35:1011-9.

47. Metro MJ, Broderick GA. Diabetes and vascular impotence: does insulin dependence increase the relative severity? Int J Impot Res 1999;11:87-9.

48. Benvenuti F, Boncinelli L, Vignoli GC. Male sexual impotence in diabetes mellitus: Vasculogenic versus neurogenic factors. Neurourol Urodyn 1993;12:145-51.

49. Rendell MS. Sildenafil improves intercourse in patients with erectile dysfunction and diabetes. EASD (Barcelona) 1998;A300:1193.

50. Tsai YS, Lin JS, Lin YM. Safety and efficacy of alprostadil sterile powder (S Po, CAVERJECT) in diabetic patients with erectile dysfunction. Eur Urol 2000;38:177-83.

51. Price DE, Cooksey G, Jehu D, Bentley S, Hearnshaw JR, Osborn DE. The management of impotence in diabetic men by vacuum tumescence therapy. Diabet Med 1991;8:964-7.

52. Ryder RE, Close CF, Moriarty KT, Moore KT, Hardisty CA. Impotence in diabetes: Aetiology, implications for treatment and preferred vacuum device. Diabet Med 1992;9:893-8.

53. Minhas S, Eardley I. Diabetic impotence. In: Carson C, Kirby R,
Goldstein I, eds. Textbook of Erectile Dysfunction, 1st edn. Oxford: Isis Medical Media Ltd, 1999:540-50.

54. Wilson SK, Delk JR Jr. Inflatable penile implant infection: predisposing factors and treatment suggestions. Diabet Med 1991;8:964-7.

55. Fairburn CG, McCulloch DK, Wu FC. The effects of diabetes on male sexual function. Clin Endocrinol Metab 1982;11:749-65.

56. Vignon F, LeFaou A, Montagnon D, et al. Comparative study of semen in diabetic and healthy men. Diabetes Metab 1991;17:350-4.

57. Dinulovic D, Radonjic G. Diabetes mellitus/male infertility. Arch Androl 1990;25:277-93.

58. Garcia-Diez LC, Corrales Hernandez JJ, Hernandez-Diaz J, Perdaz JM, Miralles JM. Semen characteristics and diabetes mellitus: Significance of insulin in male infertility. Arch Androl 1991;26:119-127.

59. Kaemmerer H, Mitzkat HJ. Ion-exchange chromatography of amino acids in ejaculate of diabetics. Andrologia 1985;17:485-7.

60. Vale J. Ejaculatory dysfunction. BJU Int 1999;83:557-63.

61. Greene LF, Kelalis PP. Retrograde ejaculation of semen due to diabetic neuropathy. J Urol 1968;98:693-6.

62. Corson SL, Lipshultz LI, McConnell J, Benson GS. Current concepts of the mechanisms of ejaculation: Normal and abnormal states. J Reprod Med 1981;26:499-507.

63. Thomas AJ. Ejaculatory dysfunction. Fertil Steril 1983;39:445-54.

64. Murphy JB, Lipshultz LI. Abnormalities of ejaculation. Urol Clin North Am 1987;14:583-596.

65. Scammel GE, Stedronska-Clark J, Edmonds DK, Hendry WF. Retrograde ejaculation: A successful treatment with artificial insemination. Br J Urol 1989;63:198-201.

66. Vernon M, Wilson E, Muse K, et al. Successful pregnancies from men with retrograde ejaculation with the use of washed sperm and gamete intrafallopian tube transfer (GIFT). Fertil Steril 1998;50:822-4.

67. Urry RL, Middleton RG, McGavin S. A simple and effective technique for increasing pregnancy rates in couples with retrograde ejaculation. Fertil Steril 1986;46:1124-7.

68. Mahadevan M, Leeton JF, Trounson AO. Noninvasive method of semen collection for successful artificial insemination in a case of retrograde ejaculation. Fertil Steril 1981;36:243-7.

69. Ohl D. Electroejaculation. Urol Clin N Am 1993;20:181-8. 